\title{
Bifrontal approach for clip ligation of bilateral ethmoidal dural arteriovenous fistulas: operative video
}

\author{
Tyler S. Cole, MD, Sirin Gandhi, MD, Justin R. Mascitelli, MD, Douglas Hardesty, MD, \\ Claudio Cavallo, MD, and Michael T. Lawton, MD \\ Department of Neurosurgery, Barrow Neurological Institute, Phoenix, Arizona
}

\begin{abstract}
Venous interruption through surgical clip ligation is the gold standard treatment for ethmoidal dural arteriovenous fistula (e-dAVF). Their malignant natural history is attributable to the higher predilection for retrograde cortical venous drainage This video illustrates an e-dAVF in a 70-year-old man with progressive tinnitus and headache. Angiogram revealed bilateral e-dAVFs (Borden III-Cognard III) with one fistula draining into cavernous sinus and another to the sagittal sinus. A bifrontal craniotomy was utilized for venous interruption of both e-dAVFs. Postoperative angiography confirmed curative obliteration with no postoperative anosmia. Bilateral e-dAVFs are rare but can be safely treated simultaneously through a single craniotomy.
\end{abstract}

The video can be found here: https://youtu.be/666edwKHGKc.

KEYWORDS ethmoidal fistula; dural arteriovenous fistula; bifrontal craniotomy; microsurgical clip ligation; video 